\title{
Government Policy as a Driver of Energy Saving in Egypt
}

\author{
Hussameldeen Bahgat ${ }^{1}$
}

\begin{abstract}
This study focuses on the Government policy and deals with the Egyptian urban problem which started in the middle of the twentieth century. In the past five decades, the government has adopted several urban development plans. Those plans have followed experiences of some developed countries which were not necessarily in line with the local conditions and priorities. In addition, governmental institutions have dealt with global trends of urban development such as the need of sustainability for the next generations. This, unfortunately, was done in a shallow way and without enough studies to determine the specific local needs and priorities. Moreover, barriers that hinder the urban development process have recently appeared. Since Egypt faces water shortage and fossil fuel crisis, the current strategies and policies, that are currently ineffective, need to be reorganized. This is just to solve the old common urban problems. This study discusses the need of the government to develop new national strategies and policies for energy saving using new approaches for sustainable urban development planning. It also discusses the need of the government to improve performance capacities and capabilities continuously. The improvement should be technological as well as organizational and social.
\end{abstract}

Keywords: government policy; sustainability; developed countries.

\section{Introduction}

In the past few years, new barriers to urban development (UD) in Egypt have appeared. The first is water shortage. Egypt has reached a state where the quantity of water available limits national UD. The second barrier lies is fossil fuel crisis. Egypt's energy production mainly depends on fossil fuel. Production is not enough for the demanded energy and the country does not have enough money to import fuels. The third barrier is climate change, one that is usually neglected or considered a secondary priority.

In order to reach global sustainable development, the sustainability and efficiency of urban energy systems should be enhanced. New plans, strategies, and regulations need to be set to save energy in case the energy resources needed for urban development are not met. This paper studies the governmental policies that deal with the technological, innovative, behavioral, and structural capacities of the Egyptian UD. It focuses on the transition towards sustainable urban development (SUD) and the tools to enhance the efficiency of urban energy systems. The study discusses the need to set new national strategies and policies which depend on new approaches of SUD planning. This is in order to improve the performance capacities and capabilities of the new energy saving 
techniques.

Egypt is an emerging country [1] whose economy and population are growing. Like other emerging countries, these economic conditions along with the increasing population have led to chaotic urbanization. Egypt heavily depends on fossil fuels for power production and already has local resources of fossil fuels. However, in the last decade, domestic demand overpassed production. "Subsequently the consumption of energy has been boosted. As a result, in the recent years, domestic supplies have fallen short of demand, due to the ongoing increase in consumption, stagnation in production, and a very generous subsidy policy which heavily contributed to increasing consumption" [2]. Egypt has to find a new approach to deal with these common urban problems. This is through developing new national strategies and policies that depend on new approaches to reach sustainable urban development planning and to continuously improve the performance capacities and capabilities.

\section{Policies and Strategies}

Egypt's present economy is high-energy and demand-intensive. The demands are met by energy yielding fossil fuels. Energy efficiency and renewable energy sources are proposed solutions and are named the 'twin pillars' of the sustainable energy policy. In the coming few pages the research explores some of the major experiences of developed countries and will use them as a guide for the Egyptian government and its institutions. It studies their plans and strategies in dealing with the energy saving necessity. This should help Egypt develop new national strategies and policies that enhance the technological, innovative, behavioral and structural capacities of Egyptian UD in its transition towards sustainable urban development (SUD). The study pays attention to the contribution of the developed countries, especially the USA and the EU and their plans and strategies for sustainable energy policy. The study suggests four strategies as reference. It uses the experiences the developed countries have had with these strategies as a driver for energy saving in Egypt.

2.1.Green building programs

2.2. Life Cycle Assessment (LCA)

2.3. Environmental construction product

2.4. Climate protection management (CPM)

\subsection{Green building programs}

On an international level, there are many institutions that contribute to setting codes that motivate energy saving. Sustainability is adopted into building codes at different levels and with varying motivations according to the government policies by which these codes abide. The approach taken reflects local social perceptions, political priorities, national policies, and economic factors. There are two major experiences that can be taken as guide in our steps to energy saving in Egypt. These two major experiences are the current status, and trends of 'sustainable' building codes adapted by individual political entities within the USA and the EU. The first example is the US Green Building Council's Leadership in Energy and Environmental Design (LEED) program. LEED is a voluntary program intended to transform the industry and is 
considered a success by a trend including sustainable design practices in building codes across the globe. The International Green Construction Code (IGCC) is the basis for which most, but not all, states in America can include sustainability in their building codes. The second example is the application of ASHRAE Standard 189.1, which is managed and developed by ASHRAE, USGBC and the Illuminating Engineering Society. The adoption of energy performance standards varies widely across the USA. On the other hand, the EU is trying to reach nearly zero energy buildings at the end of this decade per various directives like EPBD and EED. The next several years will see further modification in the process in the USA as the IGCC and Standard 189.1 will be merged.

\subsubsection{Brief history of green building programs}

Various rating systems that have been developed by organizations around the world to indicate how well a building meets its prescribed requirements. They were also made to determine whether a building design is green and what level of green it is. All systems provide useful tools to identify and prioritize key environmental issues. These tools incorporate a coordinated method for accomplishing, validating, and benchmarking sustainably designed projects. As with any generalized method, each has its own limitations and may not apply directly to every project's regional, political, and owner design intent-specific requirements.

\subsubsection{Green building rating systems, standards and codes}

In the past two decades, a movement started to develop programs that will help, encourage and provide guidance in the inclusion of sustainability measures in the design, construction, and operation of buildings. Initially, these programs were setup as measures by which a building project could voluntarily participate and achieve recognition for including recognized sustainability concepts in its design. As the concept of 'green buildings' began to take hold, some jurisdictions began to look for methods to make these sustainability measures mandatory rather than just voluntary. Therefore, these organizations began to develop and write standards and building codes.

Codes that define the level of performance that must be achieved before a building could be referred to as 'green' or sustainability-focused were thus identified as a need of the industry. Due to the wide variation in economic, social, political, and technological conditions between the various countries and jurisdictions of the world, it is not surprising that there will need to be a wide variation in the approach taken to achieve the goals of moving sustainable building design into the mainstream. This paper provides a brief synopsis of the process that has occurred in this development and a description of the state-of-the-art in the industry. The paper particularly focusing on the United States and Europe and the energy saving strategies in these two regions. Various types of sustainability programs exist that are categorized as follows:

Rating Systems - A green building rating system is intended to provide a method whereby a building project can voluntarily adapt a set of sustainability measures that meet a pre-defined set of requirements. Examples of relevant green building rating systems include BREEAM (Building Research Establishment Environmental 
Assessment Method) [3], LEED (Leadership in Energy and Environmental Design) [4] and Green Globes [5].

Guidelines - A green building guideline is a set of criteria that an outside entity has defined as design criteria or goals that the project should incorporate to minimize the overall environmental footprint. Examples include the Advanced Energy Design Guidelines (AEDG) that ASHRAE (American Society of Heating, Refrigeration and Air Conditioning Engineers) has produced with the backing up of the US Department of Energy [6].

Standards - A standard is a collection of criteria that are recognized within the industry as meeting the acceptable requirements for a level of performance. The purpose of a standard may be for adoption as the basis of a building code, or just a level of performance by which a project should be designed. In example, ASHRAE Standard 90.1 [7] is the basis of the energy codes within the USA.

Building Code - While the building permit and code compliance process vary widely across the globe, there are some common factors. First, a minimum set of criteria must be established. These criteria can be prescriptive or performance in nature. Prescriptive criteria are specific items and/or methods to meet to demonstrate compliance, while performance criteria specify a goal to be reached and may be more involved by, in example, requiring building energy simulation modeling to demonstrate compliance.

\subsection{Life Cycle Assessment (LCA)}

Because of its high environmental impact (energy and water consumption, waste production, greenhouse gases emissions...), the built environment is a key sector in facing today's energy and environmental challenges. A new approach has to be taken from the government and its institutions to help in alleviating the high environmental impact of UD, especially in the coming few years. One of the suggested approaches is the quantitative and multi-criterial life cycle assessment (LCA) methodology. According to ISO 14040 [8], it is particularly adapted to study these impacts to make the building sector more sustainable. By comparing their environmental impacts, several projects corresponding to the same functional unit can then be ranked.

Life Cycle Assessment (LCA) plays an especially important role as it aims to comprehensively determine the environmental impact of a product. Not only does it highlight individual environmental impacts or characteristics that positively impact the environment, like Eco-labels, but it also includes numerical data on the total impact (where possible) of the product over its whole life-cycle - from resource extraction, manufacture and use to its disposal - in terms of the primary energy consumption, $\mathrm{CO}_{2}$ emissions and other environmentally relevant factors [9]. The LCA is therefore a scientifically recognized tool for evaluating products.

A building life cycle assessment tool was developed and linked with an energy simulation tool to take the strong interactions between the energy and the environmental performance of buildings into account. This life cycle assessment tool was then extended at the urban level to evaluate the environmental impacts of a district that includes many 
buildings, streets, public spaces and technical networks. Building and neighborhood design alternatives can thus be compared, providing assistance in the decision process. However, the reliability of LCA is essential to guide the decision maker towards energy saving and sustainability.

The importance of Life Cycle Assessment (LCA) in building evaluation is increasing. For some building certifications like the German DGNB [10] and BNB [11], it is a mandatory part of the certificate. Sustainability criteria has also become more important as a new approach for evaluating architecture, urban design and planning [12]. Nowadays, in developed countries, the architects have to describe their approach in reducing the environmental impact, including the saving of energy and greenhouse gas emissions. In short, decisions made in the early phases of the design have significant consequences since they define the general conditions for the subsequent planning process [13]. They have the biggest impact on energy demand [14]. Therefore, an optimization of the design with regard to a low environmental impact can best be achieved in early design stages.

The quantitative evaluation of the environmental impact through LCA requires a calculation of the energy demand and a bill of quantities. However, the most fundamental decisions, such as building form, orientation and window arrangement, are often made by architects in the early design stages, with little or no involvement of a simulation software [15]. In Germany, an energy demand calculation is mandatory for building applications. Most design decisions are made and changes to the design usually require high effort.

\subsection{Environmental construction product}

Egypt has plenty of contaminated industries like the ceramic industry, the cement industry, and other industries which cause air pollution due to the large amount of air waste and exhaust coming out from the factories. This pollution creates serious respiratory diseases and cancer due to the inhaled particulates in the air (dust and soot, hydrocarbons and heavy metal compounds). To alleviate this pollution problem, the government and its institutions have to focus on using environmental industries and to issue regulations to limit the contaminated industries and encourage manufacturers to make their products based on environmental limitations.

The most important arguments are the objective number-based representation and assessment of the whole life cycle by an LCA rather than the accentuation of individual product characteristics. It is apparently not just the characteristics of individual building products which are of interest but also the building as a whole. Based on these arguments, products with LCA-based environmental product declaration (EPD) are granted a monopoly position for inclusion in (both state and private) building evaluation systems at the national level (above all in Germany, UK and France) as well as at the EU level. They also get a proof of performance for CE-marking.

EPDs are currently favored by politicians and the large building product manufacturers. This is despite the fact that an EPD does not contain any evaluative statements that might indicate that the product exhibits a particularly good ecological performance. An EPD is simply the sober calculation of data on the environmental impact. It is desired that an EPD documents the poor environmental characteristics of a product. A positive 
environmental argument can only be made using an EPD in such a manner that a particular parameter - such as the energy consumption in manufacturing - is lower than that of a competitor. Such a comparison is not desired by the industry and is even impeded by national egotism.

The building industry also has great interest in ensuring that the state bodies and the market favor environmental declarations over eco-labels. The most important argument for them, one that is rarely openly mentioned, is the restriction of competition in the field of environmental issues: Where an environmental label will single out a product from its competitors, a declaration is not bound by the fulfillment of benchmarks. It actually constitutes an obstacle to product comparison. It is, above all, the large industrial trade associations such as the German Building Materials Association (BBS) which are disparaging about certifications conducted by environmental labels, and at the same time, recommend the introduction of EPDs to their members.

The stated goal of the building industry then was to use the meaningless average value to supply proof of the sustainability characteristics which were demanded by the Government and the market. This would save the money needed to be spent on detailed analysis of each of the local production site conditions. It would also exclude any environmental competition among the companies as they all have to supply the same figures. This is exactly how the building industry initially asserted itself: Both the various systems of building evaluation such as DGNB and BNB, bream or LEED as well as the contract award directive 2014/24/EU confirm that these generic EPDs are accepted as proof. At this level, the EPD, as a tool for building product selection guidance, has already bowed out.

However, even if a company does not shy away from this expense and produces a specific EPD for a particular type of production, this is not worth much in terms of the utility of this declaration as tool for guidance: A great deal of expertise is required to interpret the bare numerical values in an EPD. Many of the characteristics of greatest importance to the consumer and construction professional, such as an emissions test or the use of certain harmful substances, are not contained within the EPD. An additional limitation - despite all the available official standards - is that the LCAs and EPDs come from different providers and systems that are not comparable with each other. There are numerous national life-cycle assessment programs, each containing different Product Category Rules (PCR) on how particular environmental impacts are to be calculated and weighted. It has also become standard practice that there be only one EPD system provider in each country which, at the same time, also supplies the data basis for the national building certification programs (see Fig. 1). 


\section{EPDs}
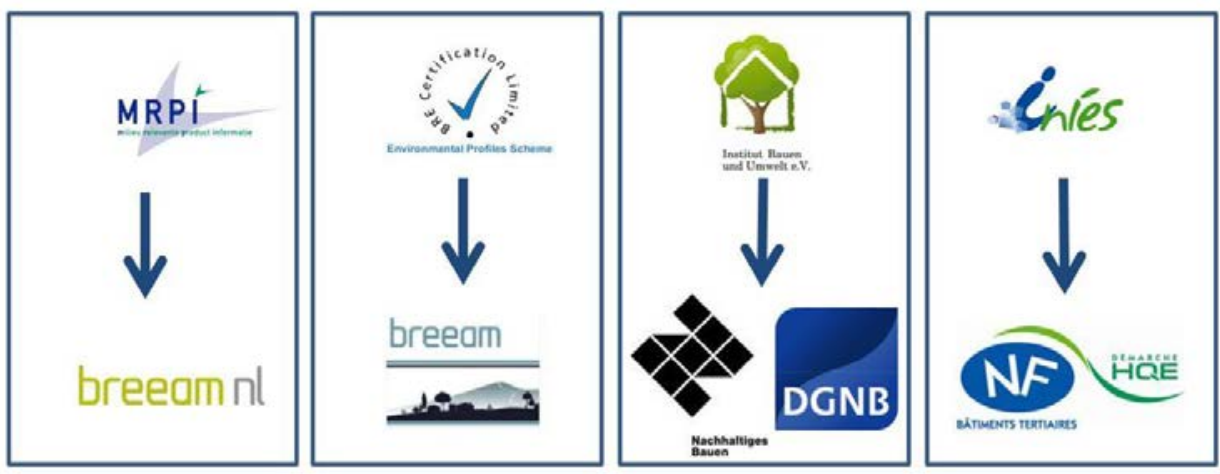

\section{Green Building Rating Schemes}

Figure 1 - Present Situation of National Building Certification Based on National EPD Programs (with Thanks to ECO-platform GaBi)

An international standardization of the systems, ECO-Platform, is an umbrella organization of 13 European EPD programs. What it tries to achieve is still far off as this would necessarily entail changes in all of the national systems. The ECO-Platform members have currently not achieved more than a system of mutual recognition. The various EPD providers in Europe still continue to supply non-comparable data. In addition, the use of different software, where the majority of European providers use the Swiss database eco-Invent while the Germans use the background database, leads to incomparable results. The industry also views this as an obstacle to the spread of EPDs as it is active across the European market and does not want to produce a new EPD for each country. This situation means that the EPD doesn't provide the environmentally conscious planner or investor with any product selection guidance.

\subsection{Climate protection management (CPM)}

One of the key factors for sustainably built environments is not only a successful municipal or corporate climate protection strategy, but also a well-trained team of professional climate protection managers (CPM) who operate as networkers and coordinators. Due to the enormous complexity of the field of work of climate protection, it is highly advisable to provide an educational branch, which is specialized on the different technical, social and methodical requirements in the field of climate protection management.

Private households, the economy, industries, traffic, and services generate the highest amounts of $\mathrm{CO}_{2}$ emissions. A network of European cities, counties, and municipalities has formed a climate protection alliance, which aims to reduce the exhaust of greenhouse gases in urban spaces by $10 \%$ every five years and totally up to $50 \%$ until 2025 compared to 1990 [16]. Unfortunately, these set goals cannot be reached within the planned periods or even at all [17]. Not least to save costs, town councils and companies around Europe 
make an effort to reduce their carbon footprint. Multiple possibilities and ideas for climate protection are already available, but there is still lack of climate protection managers with sufficient technical and economic background knowledge to guarantee a fast implementation of these climate protection strategies. Furthermore, climate protection managers are supposed to have a high degree of motivation to fulfill the complex every-day tasks. They are supposed to manage technical problems as well as interact and moderate between different social groups and representatives like city councils, politicians, companies, or citizens. Town councils and companies ought to look for qualified professionals to implement their climate protection strategies. Studies and advanced training programs that directly address prospective climate protection managers and are able to cross the gap between technical and social education are very rare.

The demand on the skills of municipal climate protection managers is characterized by a high degree of inter-discipline. Among these demands climate protection managers have to face in practice are communication skills to mediate information to different target groups like experts, municipal politicians, media representatives, consumers, or investors. Furthermore, a profound comprehension of economic relationships, knowledge of relevant technological branches and the interconnectivity between these branches as well as knowledge of municipal administrative structures is essential. In Germany, for example, only few towns and municipalities have skilled employees in all of these fields. The complete job specifications for qualified employees for climate protection management in Germany has not been investigated in detail yet. Thus, the first part of the project is a nationwide survey of towns and municipalities regarding the duties and activities of already active and future climate protection managers. The surveyed climate protection managers have been interviewed about the following topics:

- $\quad$ Educational background,

- $\quad$ Task priorities in the every-day work life of climate protection managers,

- Approaches for improvement of the necessary skills to perform the work as a climate protection manager (professional training, special training, learning by doing),

- Relevant topics for a study course in the field of climate protection management.

\section{Conclusion}

It can be summarized that Egypt is facing water shortage, fossil fuel crisis, scarcity in lots of resources. Thus, Egypt has to rethink the current strategies and policies that are already ineffective and unsatisfactory. In most cases, the laws and regulations available are not sufficient enough to fulfill the prominent role they should play for energy saving strategies. Therefore, more awareness needs to be created concerning the importance of setting up reliable strategies and regulations. This is because consistent and up-to-date data are needed to form the foundation for the discussion on energy saving strategies in Egypt.

The Egyptian government and its institutions have to aspire from the developed countries' contributions, plans, and strategies in dealing with the energy saving necessity, 
through developing new national strategies and policies to enhance the Egyptian UD in its transition towards sustainable urban development SUD. The study pays attention to the contribution of the developed countries especially the USA and the EU and their plans and strategies for sustainable energy policy. It suggests four strategies as guide to aspire the experiences that the developed countries have had as a driver of energy saving in Egypt. The first is setting green building programs. The second is to use LCA to assess the environmental performance of buildings. The third is to issue regulations to limit the contaminated industries and encourage manufacturers to make their products based on environmental limitations. The fourth is to create well-trained teams of professional climate protection managers (CPM).

\section{References}

[1]MSCI emerging markets index overview, June 30 2015, http://www.agf.com/institutional/globalresources/files/quarterly-report/inst270-msci-emusd.pdf

[2] Hegazy, K.(2015). Egypt's Energy Sector: Regional Cooperation Outlook and Prospects of Furthering Engagement with the Energy Charter. Occasional Paper, Energy Charter Secretariat, Knowledge Centre.

[3]BUILDING RESEARCH ESTABLISHMENT, BREEAM: Building Research Establishment Environmental Assessment Method, www.breeam.org

[4]U.S. GREEN BUILDING COUNCIL, LEED: LEADERSHIP IN ENERGY ANDENVIRONMENTAL DESIGN, http://www.usgbc.org/leed

[5] GREEN GLOBES http://www.greenglobes.com/home.asp

[6]ASHRAE, Advanced Energy Design Guides, Atlanta. Available online: https://b .ashrae.org/standardsresearch--technology/advanced-energy-design-guides

[7] ASHRAE, ANSI/ASHRAE/IES Standard 90.1-2013, Energy Standard for Buildings Except Low-Rise Residential Buildings, Atlanta: ASHRAE, https://www.ashrae.org

[8] ISO 14040:(2006). "Environmental management - Life cycle assessment - Principles and framework", last reviewed in 2010 .

[9] Thomas, S. ( 2016) LCA, EPD and Labels - How to Select Green Building Products?. International Conference on Sustainable Built Environment Strategies - Stakeholders - Success factors 7th 11th March.

[10] DGNB, “DGNB system,” http://www.dgnb-system.de/en/. Accessed: 04-Apr-2015.

[11] BBSR, "BNB system," https://www.bnb-nachhaltigesbauen.de. Accessed: 04-Apr-2015.

[12] Fuchs, M. (2013) "Nachhaltigkeitsorientierte Architekturwettbewerbe Kriterien und Indikatoren zur Integration von Nachhaltigkeitsanforderungen in Wettbewerbsverfahren sowie Empfehlungen und Werkzeuge für die praktische Durchführung," TU Darmstadt.

[13] Paulson Jr, B. C. (1976) Designing to Reduce Construction Costs," J. Constr. Div., vol. 102, no.4, pp. $587-592$.

[14] Hegger, M. Fuchs, M. Stark, T. and Zeumer, M. (2007) Energie Atlas: Nachhaltige Architektur. Birkhäuser,

[15] Picco, M. Lollini, R. and Marengo, M. (2014). Towards energy performance evaluation in early stage building design: A simplification methodology for commercial building models," Energy Build., vol. 76, pp. 497-505, Jun.

[16] Homepage of „Climate Alliance“; www.klimabuendnis.org

[17] LECHTENBÖHMER, S., SEIFRIED, D., et. a., (2009).Smart City - Bausteine auf dem Weg zu einer CO2-armen Stadt“; Energiewirtschaftliche Tagesfragen,. 